\title{
Ameliorative Effects of Exposing DBA/2J Mice to an Augmented Acoustic Environment on Histological Changes in the Cochlea and Anteroventral Cochlear Nucleus
}

\author{
James F. Willott, ${ }^{1}$ Lori S. Bross, ${ }^{2}$ and SAndra McFadden ${ }^{3}$ \\ ${ }^{1}$ Department of Psychology, University of South Florida, 4202 E. Fowler Ave. PCD4118G, Tampa, FL 33620, USA \\ ${ }^{2}$ Department of Biological Science, Northern Illinois University, DeKalb, IL 60115, USA \\ ${ }^{3}$ Center for Hearing and Deafness, State University of New York at Buffalo, 215 Parker Hall, Buffalo, NY 14214, USA
}

Received: 17 February 2005; Accepted: 18 April 2005; Online publication: 28 June 2005

\begin{abstract}
DBA/2J (D2) mice, which exhibit very early progressive sensorineural hearing loss, were treated nightly with an augmented acoustic environment (AAE) initiated before the onset of hearing, and consisting of repetitive bursts of a 70-dB sound pressure level (SPL), $4-25 \mathrm{kHz}$ noise band. At 55 days of age, AAEtreated mice exhibited less elevation of auditory brainstem response thresholds, fewer missing hair cells, and greatly reduced loss of anteroventral cochlear nucleus (AVCN) volume and neuron number compared to untreated control mice. It was hypothesized that the central neuroprotective effect was associated with increased afferent input to AVCN neurons evoked by the AAE as well as a healthier cochlea.

Keywords: mice, sensorineural hearing loss, augmented acoustic environment, cochlear nucleus, hair cells
\end{abstract}

\section{INTRODUCTION}

Genetic progressive sensorineural hearing loss in DBA/2J (D2), C57BL/6J (B6), and other inbred strains of mice is ameliorated by treatment with an

Correspondence to: James F. Willott - Department of Psychology, University of South Florida, 4202 E. Fowler Ave. PCD4118G, Tampa, FL 33620, USA. Telephone: (813) 974-8298; fax: (813) 974-4617; e-mail: jimw@niu.edu augmented acoustic environment (AAE). The AAE used thus far consists of nightly exposure to repetitive noise bursts $(70 \mathrm{~dB}$ SPL sound pressure level re: $20 \mu \mathrm{Pa}$ ) with maximum energy between about 4 and $25 \mathrm{kHz}$ (Turner and Willott 1998; Willot and Turner 1999; Willott et al. 2000). AAE treatment slows age-related elevation of auditory brainstem response (ABR) thresholds, increases the size of acoustic startle responses, and strengthens the ability of tones to inhibit startle in the prepulse inhibition paradigm. The histological correlates of AAE treatment in the cochlea and anterior ventral cochlear nucleus (AVCN) of $\mathrm{B} 6$ mice were recently reported by Willott and Bross (2004), the results of which are discussed below. The present study extends the morphological study to D2 mice.

The time course and severity of hearing loss differ greatly between the $\mathrm{D} 2$ and $\mathrm{B} 6$ strains. In $\mathrm{B} 6$ mice high-frequency hearing loss is first observed at about two to three months of age (young adulthood), progresses gradually, and becomes profound during the second year of life (Ding et al. 2001; Erway et al. 1993; Henry and Chole 1980; Li and Borg 1991; Mikaelian 1979; Willott 1996). D2 mice exhibit very early hearing loss that is evident even at three weeks of age (Ralls 1967; Willott 1981; Willott et al. 1982), about a week after the onset of hearing and prior to complete maturation of the central auditory system (Willott 1981; Willott et al. 1984). D2 mice become virtually insensitive to high-frequency tones $(>15 \mathrm{kHz})$ by two months of age. ABR thresholds of 55-day-old D2 mice are roughly comparable to those of 12- to 
14-month-old B6 mice (the age used in the Willott and Bross 2004 study), so the present study focused on D2 mice of that age to compare findings with those obtained with $\mathrm{B} 6$ mice.

Degeneration of outer hair cells (OHCs), inner hair cells (IHCs), and other cochlear tissue underlie progressive hearing loss in B6 and D2 strains (Ding et al. 2001; Henry and Chole 1980; Hequembourg and Liberman 2001; Ohlemiller and Gagnon 2004; Spongr et al. 1997; Willott 1996; Willott et al. 1995). Willott and Bross (2004) assessed cochlear correlates of long-term, nightly AAE treatment on B6 mice at 12-14 months of age (an age at which high-frequency hearing loss is severe). AAE treatment resulted in lessened severity of the progressive loss of OHCs, with the tonotopic regions of cochlea that benefited roughly corresponding to the frequency spectrum of the AAE (i.e., mid-cochlea). Effects on IHCs were less clear. One aim of the present study was to determine if similar cochlear AAE effects would occur in D2 mice.

In the absence of AAE treatment, the AVCNs of both $\mathrm{B} 6$ and $\mathrm{D} 2$ mice exhibit a progressive loss of tissue volume (15-20\%) and number of neurons (about $20 \%$ in B6; $25-35 \%$ in D2) (Willott and Bross 1996). In each strain these changes occur during the period that progressive sensorineural hearing is becoming significant - between three and seven months in B6 and between three weeks and about two months in D2. The second aim of this study was to determine the effects of AAE treatment on AVCN morphology in the D2 model.

D2 mice were given AAE treatment or no treatment (controls), and ABR thresholds, hair cell counts (cytocochleograms), and assessment of AVCN volume and neuron number were performed as in the previous study on B6 mice (Willott and Bross 2004). In order to maximize potential AAE effects on the AVCN, AAE treatment was initiated prior to weaning and before the onset of hearing which occurs at about 12 days of age (Shnerson and Pujol 1983). An additional group of $\mathrm{D} 2$ mice received "delayed" AAE treatment (beginning 10 days before euthanasia) which has only minimal effects on hearing loss in D2 mice (Turner and Willott 1998).

\section{METHODS}

\section{Subjects}

All mice were of the DBA/2J strain and were secondor third-generation offspring of stock obtained from the Jackson Laboratory (Bar Harbor, ME). Room temperature was maintained between 23 and $24^{\circ} \mathrm{C}$ and a 12-hour light/dark schedule was used.

Mice were weaned at 23 days of age, given ad libitum access to Purina rodent chow and tap water.
Control mice were reared under relatively quiet conditions, as indicated by octave band-level measurements made with a Brüel and Kjær Type 2203 Precision Sound Level Meter coupled to a Type 1613 octave band filter. Sound pressure levels ranged from $50 \mathrm{~dB}$ SPL (re: $20 \mu \mathrm{Pa}$ ) at $2 \mathrm{kHz}$ to $24 \mathrm{~dB}$ at $31.5 \mathrm{kHz}$.

Nightly treatment was given to 10 male and 7 female mice beginning around the time of birth ("early AAE treatment") until age 55 days when they were euthanized. ABR thresholds were obtained at ages 30 and 55 days. All but one of the mice were then used for morphological assessment of the AVCN. Hair cell counts were obtained from six mice. An additional four mice were euthanized at 55 days of age after treatment was initiated only 10 days earlier ("AAE for 10 days").

Control mice (not treated with the AAE) used for ABR thresholds were four male and three female mice aged 30 days and eight male and seven female mice aged 55 days. Two males and two females were used for cochleograms at age 55 days. AVCN measurements were made on control mice of both sexes at 35 days $(n=6)$ and 55 days $(n=4)$.

To better evaluate AAE effects on AVCN volume and neuron number, additional data are presented graphically from control mice used in earlier studies (Turner and Willott 1998; Willott and Bross 1996). The ages of these controls were: 23 days $(n=5)$, 31 days $(n=5), 45$ days, $n=4 ; 50$ days $(n=5), 55$ days, $\mathrm{n}=4,70$ days $(n=7)$.

All procedures conformed to NIH guidelines for use of animals in research and were approved by the Institutional Animal Care and Use Committee of Northern Illinois University.

\section{Procedures}

Exposure to the AAE. A dam and her pups were placed in a plastic cage $(12 \times 13 \times 30 \mathrm{~cm})$ before the pups were 12 days old. Here they received consecutive 12-hour nights of AAE until they were euthanized at age 55 days.

The procedure has been described in detail in previous papers (Willott and Turner 1999; Willott and Bross 2004). To produce the AAE, Radio Shack Supertweeters were mounted above the cages. The signal was a broadband noise (rise $/$ fall $=10 \mathrm{~ms}$, duration $=200 \mathrm{~ms}$, rate $=2 / \mathrm{s}$ ) of $70 \mathrm{~dB}$. SPLs measured within third-octave bands (Brüel \& Kjær Type 2606 measuring amplifier connected to an external bandpass filter and 1/8-in. microphone) showed the spectral peak to be between about 8 and $20 \mathrm{kHz}$ (SPLs > $55 \mathrm{~dB}$ ), rolling off above and below this range; third octaves encompassed by a range of about 4-25 kHz were $>50 \mathrm{~dB}$ SPL. SPLs above and below this were near or at ambient levels. The signal was 
automatically timed to be on during the 12-hr dark cycle.

ABR thresholds. The procedures for obtaining ABR thresholds are described in detail elsewhere (Turner and Willott 1998). Briefly, acoustically calibrated stimuli were delivered from a Radio Shack Supertweeter in the free field in a room that was anechoic for high frequencies $(>1 \mathrm{kHz})$. Tucker-Davis Technology hardware and software were used for stimulus production and signal averaging. A maximum sound pressure level (SPL re: $20 \mu \mathrm{Pa}$ ) of $80 \mathrm{~dB}$ was employed for all stimuli. Mice were anesthetized with Avertin (tribromoethanol; $5.3 \mathrm{mg}$ per $10 \mathrm{~kg}$ body weight, i.p.) or sodium pentobarbital (Nembutal, 1.2 $\mathrm{mg}$ per $\mathrm{kg}$, i.p.) and kept warm with a heating pad during $\mathrm{ABR}$ recordings (ABRs did not differ as a function of anesthetic). A subdermal (active) needle electrode was inserted at the vertex, and a grounded metal bite bar served as the reference electrode. Preamplifier filters were set at $100 \mathrm{~Hz}$ high pass and $3000 \mathrm{~Hz}$ low pass.

Mice were tested with tone pips (1 ms rise/fall; 3 ms duration; 4, 8, 12, 16, and $24 \mathrm{kHz}$ (D2 mice do not respond to higher frequencies). ABR thresholds were obtained for each frequency by reducing the SPL at $10 \mathrm{~dB}$ steps and finally at 5-dB steps to identify the lowest level at which an ABR could be recognized. If ABRs could not be obtained with the maximum SPL of $80 \mathrm{~dB}$, a nominal threshold of $85 \mathrm{~dB}$ was assigned. Thresholds were evaluated from records off-line by two independent, experimentally blind observers. Minor discrepancies in thresholds were resolved, subject to agreement by both observers.

Histological preparation. Mice were anesthetized deeply with sodium pentobarbital, and intracardially perfused with physiological saline followed by buffered neutral $10 \%$ formalin for $20 \mathrm{~min}$. The brain was removed from the skull and stored in fixative; one cochlea was used for hair cell counts.

Cytocochleograms. Procedures for hair cell counts were routine and are described elsewhere (Willott and Bross 2004). Cochleas were removed with a portion of temporal bone and decalcified. The basilar membrane was dissected out, stained with Ehrlich's hematoxylin, laid flat in a drop of glycerine on a slide, and cover-slipped. Cell counts were performed at $100 \times$ magnification. In each ocular field (approximately $0.12 \mathrm{~mm}$ ) proceeding from apex to base, the number of IHCs and OHCs (in each of three rows) were counted. The number of IHCs and OHCs was computed as a function of distance from the apex in order to obtain a cochleogram: the mean number of hair cells within $0.12 \mathrm{~mm}$ lengths of the organ of Corti at 0.6-mm intervals from apex to base (OHC counts are the sum of the three rows). Counts are presented graphically in the figures mapped to correspond with cochleotopic frequency representation along the basilar membrane, synthesized from the cochleotopic maps of Ehret (1983) and Henry and Chole (1980).

Preparation of AVCN slides. The methods were the same as those employed in earlier studies, as described by Willott and Bross (2004): Tissue was dehydrated, cleared, infiltrated with Paraplast Plus under vacuum, and embedded in Paraplast Plus in the frontal plane at a standard angle of orientation. Serial sections were cut at $10 \mu \mathrm{m}$, mounted on slides, and stained with Cresyl violet (Nissl stain) and in some cases counterstained with Luxol fast blue (for myelinated fibers).

AVCN morphological measurements. Measurements were made from frontal sections extending from the rostral pole of an AVCN to its caudal extent, defined as the last section rostral to the eighth nerve root (this was also at the rostral extent of the dorsal cochlear nucleus in this plane of sectioning). Using a microscope drawing tube, the outline of the AVCN in every fifth serial section was traced onto graph paper whose grid squares were calibrated to equal $100 \times$ $100 \mu \mathrm{m}$ and used to guide the location of areas evaluated in each tissue section (see below), and to determine AVCN volume with the aid of a Jandel SigmaScan image analysis system. AVCN volume was determined by multiplying the mean AVCN area of all sections measured $\left(\mu \mathrm{m}^{2}\right) \times$ the section thickness $(10 \mu \mathrm{m}) \times$ the number of AVCN sections in that subject $\times 5$ (because only every fifth section was measured). No adjustment was made for shrinkage of tissue, which is minimal with the formalin fixative.

For cell counts, the reticle was positioned to coincide with a graph square from an AVCN drawing. Then, all neurons within the $100-\mu \mathrm{m}^{2}$ reticle were counted using a $1000 \times$ oil immersion. This was done for all $100-\mu \mathrm{m}^{2}$ squares within a traced AVCN section. Criteria for identification of neurons were a palestaining nucleus with a nucleolus and stained Nissl substance within the cytoplasm (thus, granule cells were excluded). Age-related changes in the size of AVCN neurons of D2 mice are negligible and have no effect on packing density or cell counts. No attempt was made to categorize neurons as spherical or multipolar cells (the major cell types within the AVCN). The cell types are similar in size and often difficult to distinguish in the mouse AVCN (see Trettel and Morest 2001), and this avoids the possibility that unanticipated age- or AAE-related changes might confound typing of neurons.

For each AVCN section examined, the neuronal packing density was computed (the number of neurons/volume). To obtain the total number of neurons for the entire AVCN, the mean neuronal density for all sections was multiplied by the total volume of the AVCN, computed as described above. 
Prior to completing determinations of neuronal density and number, a "split cell" correction factor was employed. The size of nucleoli (defining feature of all neurons counted) was measured on a sample of neurons in each subject group and used to estimate the number of neurons that would be "split" by sectioning. This resulted in a split cell factor of 0.88 for all groups. The total cell count was multiplied by the correction factor, so that neuronal density would not be overestimated by double counting of "split" cells. This method has been empirically verified in mouse AVCN by directly measuring the percentage of neurons that would be "split" by $10-\mu \mathrm{m}$ sections horizontal and sagittal planes, orthogonal to the frontal plane (Willott et al. 1987).

Dorsoventral distribution of neuron counts. In addition to estimating the overall number of AVCN neurons in each mouse, the dorsoventral profile was determined as well. Two "standard" frontal sections were examined from each mouse. The anterior section was $250 \mu \mathrm{m}$ caudal to the rostral pole of the AVCN and the posterior section was $350 \mu \mathrm{m}$ caudal to the rostral pole. These sections lie, respectively, within the anterior and posterior divisions of the AVCN in the atlas of Trettel and Morest (2001), where additional cytoarchitectonic details may be found. Importantly, tonotopic frequency representation is roughly orthogonal to the dorsoventral axis (i.e., in horizontal "slabs") in these sections (Ryugo et al. 1981; Willott et al. 1982). Therefore, the number of neurons in successive $100-\mu \mathrm{m}$ horizontal slabs was determined for each mouse using the methodology described earlier. A dorsoventral locus of "0" was assigned to the slab that was midway between the dorsal and ventral AVCN borders. Other slabs were referenced to the following: $+100,+200$, etc., dorsally and -100 , -200 , etc., ventrally.

\section{RESULTS}

\section{ABR Thresholds}

Evaluation of potential sex effect. Preliminary ANOVAs $($ Sex $\times$ Frequency) were performed on 30 - and 55day-old control mice and AAE-treated mice at both ages to assess possible sex differences. Neither the main effect of Sex nor Sex $\times$ Frequency interactions were significant in any group. Therefore, sexes were combined for subsequent ANOVAs.

ABR thresholds are shown in Figure 1 for mice given early AAE treatment and for controls. It is apparent that, at both 30 and 55 days of age AAEtreated mice had lower thresholds than controls, and these observations were confirmed by two-way mixed ANOVA (Group $\times$ Frequency, with Frequency as a repeated measure). At both ages, main effects of
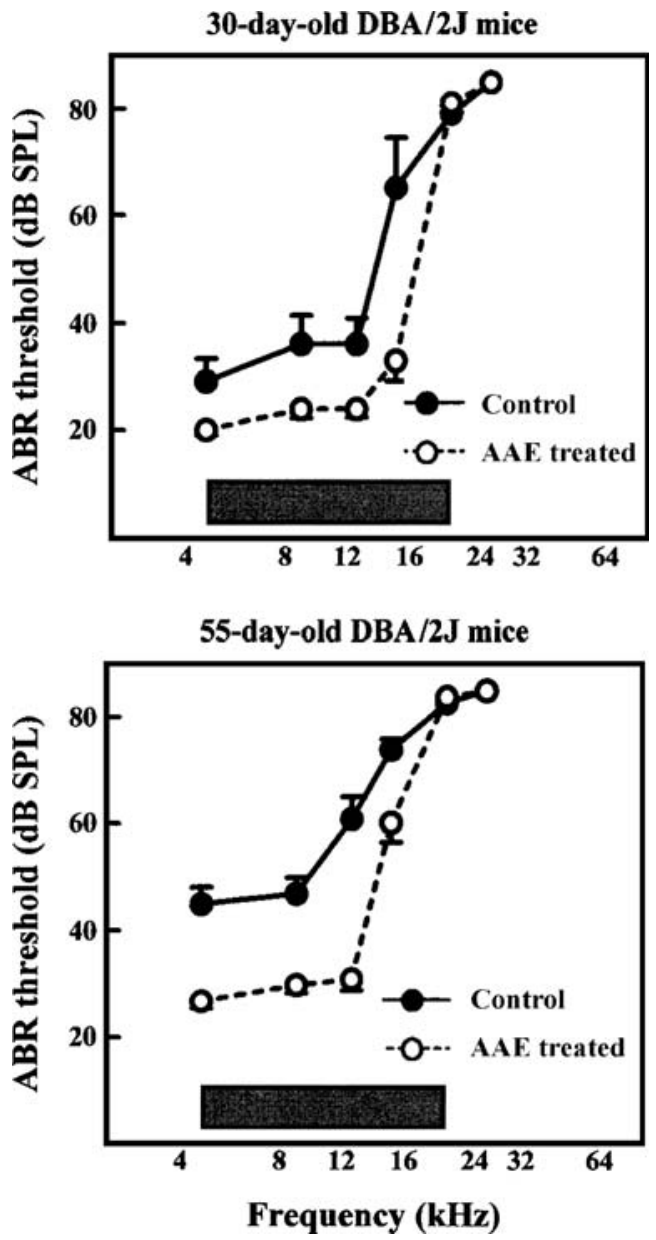

FIG. 1. ABR thresholds of young DBA/2J mice (means and SEMs). Mice were tested at 30 days of age (upper panel) and 55 days of age (lower panel). AAE-treated mice (open circles) were treated nightly with the AAE beginning before 12 days of age. The cross-hatched bar approximates the effective frequency spectrum of the AAE noise band (see text). AAE-treated mice had lower thresholds at tested frequencies below $24 \mathrm{kHz}$. Note that ABRs could not be obtained for $32 \mathrm{kHz}$ tones and higher because of basal cochlear damage; 85 $\mathrm{dB}$ "thresholds" are shown for graphic perspective with respect to the frequency representation of the normal mouse cochlea (i.e., the $32-64 \mathrm{kHz}$ points were not obtained from ABRs).

Group $(F>11.9 ; p<0.002)$ and Group $\times$ Frequency interactions $(F>11 ; p<0.0001)$ were significant. Follow-up Tukey's tests for paired comparisons showed that one-month-old mice exposed to the AAE had lower thresholds than controls at 8, 12, and $16 \mathrm{kHz}$, whereas 55-day-old treated mice had lower thresholds at 4, 8, 12, and $16 \mathrm{kHz}$. Almost all mice had thresholds at or near $85 \mathrm{~dB}$ for the $24 \mathrm{kHz}$ stimulus. D2 mice (treated and control) have thresholds greater than $85 \mathrm{~dB}$ at higher frequencies and these were not included in statistical analyses.

The ABR threshold data indicate that early AAE treatment ameliorated hearing loss for frequencies encompassed by the AAE noise band. However, thresholds at $16 \mathrm{kHz}$ were elevated substantially-by 

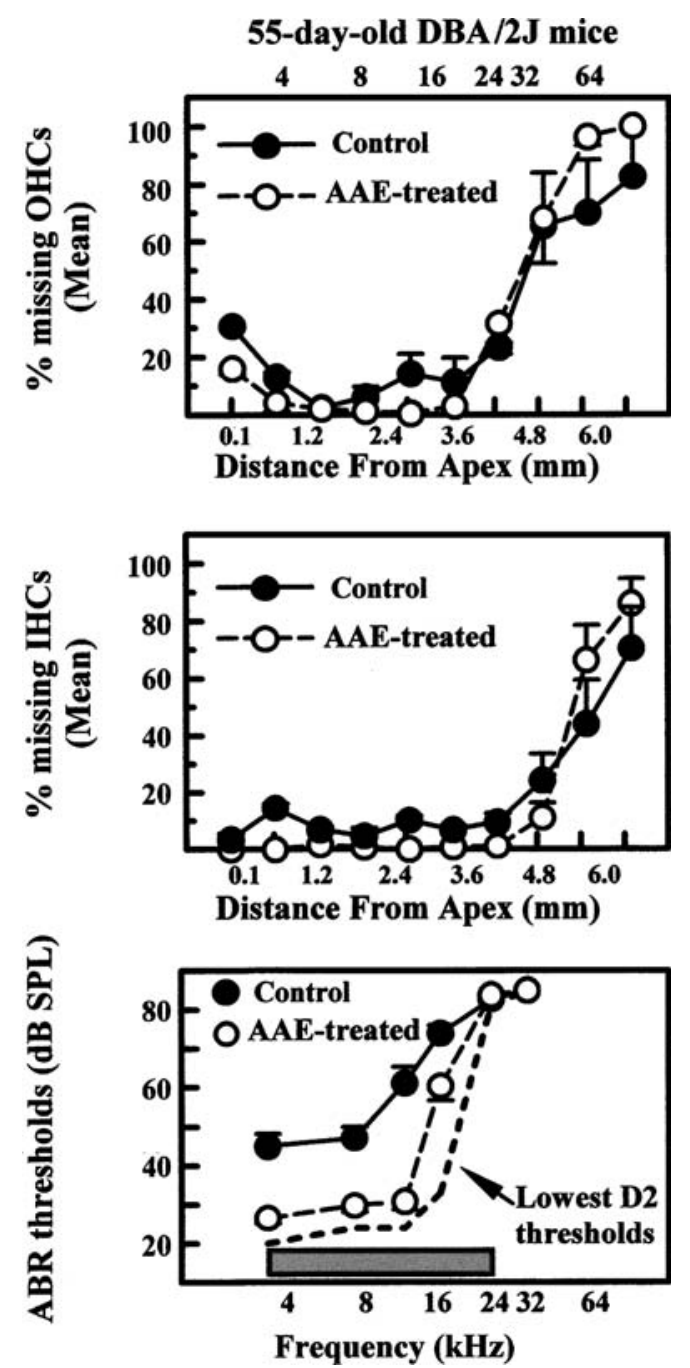

FIG. 2. OHC cytocochleograms, IHC cytocochleograms, and ABR thresholds of 55-day-old DBA/2J mice (means and SEMs). AAEtreated mice (open circles) were treated nightly with the AAE beginning before 12 days of age. The frequency scale on the ABR graph abscissa (lower panel) corresponds to the cochlear frequency map (distance from apex) of cytocochleograms (upper and middle panels) and also appears over the upper panel. The cross-hatched bar approximates the effective frequency spectrum of the AAE noise band (see text). The ABR thresholds are redrawn from those in Figure 1; the "lowest D2 thresholds" are those of 1-month-old AAE-treated mice, the lowest we have observed in this strain), and serve as a reference for the likely optimal hearing in D2 mice younger than 1 month. Treated mice had significantly more IHCs and OHCs in the 1.2- to 4.2-mm segments, but not in the apex or extreme base (note large SEMs in the latter region).

about $30 \mathrm{~dB}$ - between 30 and 55 days, despite AAE treatment. This is supported by an ANOVA for repeated measures comparing thresholds at 30 and 55 days $($ Age $\times$ Frequency). The Age $\times$ Frequency interaction was significant $\left(F_{4,128}=17.74, p<\right.$ 0.0001 ) and follow-up Tukey's test showed the threshold at $16 \mathrm{kHz}$ to be higher in 55-day-olds.
Hair cells

Analysis of cochleograms from 55-day-old mice suggests that AAE treatment initiated early has a beneficial effect on OHC and IHC loss. Figure 2 shows the mean cochleograms for OHCs and IHCs of 55-day-old mice. To assess the effects of AAE treatment, analysis focused on the region that would be stimulated by the AAE spectrum (1.2- to 4.2-mm segments). Treated mice had significantly more OHCs $\left(F_{1,8}=6.435, p=0.035\right)$ and IHCs $\left(F_{1,8}=92.02, p<\right.$ $0.0001)$ than controls. There was almost no loss of OHCs or IHCs in this region of AAE-treated mice, but controls had lost hair cells, suggesting a relationship between amelioration of hair cell loss and ABR thresholds.

\section{AVCN volume and neuron counts}

Statistical comparisons were made for 55-day-old mice that were exposed to the AAE prior to the onset of hearing (AAE-treated), 55-day-old controls, and an additional group of 55-day-old mice given delayed AAE treatment for only 10 days prior to euthanasia. Figure 3 shows AVCN volumetric data for these mice along with nonexposed D2 mice of various ages that

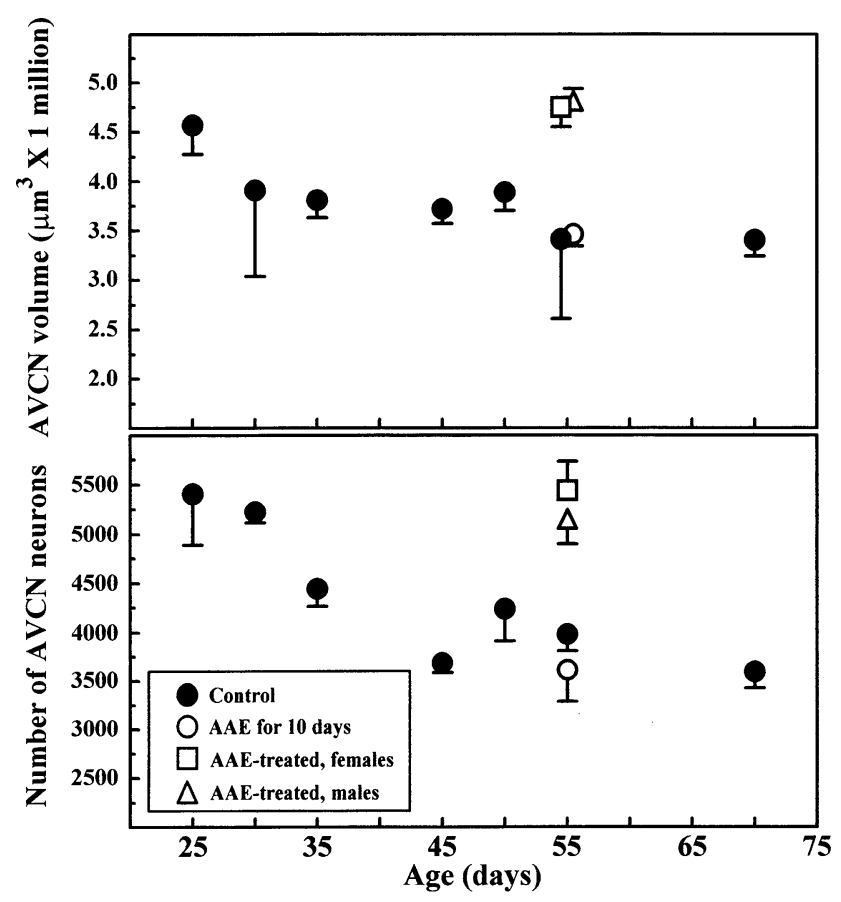

FIG. 3. AVCN volume and number of neurons for groups of D2 mice of various ages (means and SEMs). Data from some control groups are from Willott and Bross (1996): 23 days, $n=5 ; 31$ days, $n$ $=5 ; 50$ days, $n=5 ; 70$ days, $n=7$. AAE-treated males and females received nightly treatment beginning prior to 12 days of age; these volumes and neurons numbers are significantly greater than those of like-aged controls or mice receiving delayed treatment (for 10 days). 
show how D2 mice exhibit a decrease in AVCN volume after 23 days of age, which levels off thereafter. AVCN volume of 55-day-old males and females given early AAE treatment do not differ from one another and are virtually unchanged from that of the 23-day-olds. Compared to age-matched controls and mice given treatment for only 10 days, volume is significantly greater in AAE-treated mice, as indicated by a one-way ANOVA with sexes combined $\left(F_{2,21}=4.79, p<0.02\right)$.

The number of AVCN neurons in the same mice are also shown in Figure 3. The number of neurons decreases between 30 and 45 days of age in control mice, but this is not the case for AAE-treated mice. They have significantly more neurons than agematched control mice or mice given 10-day, delayed treatment $\left(F_{2,21}=12.41, p=0.0003\right)$.

\section{Dorsoventral distribution}

Figure 4 shows the mean number of neurons in two standard AVCN sections presented as a function of the dorsoventral distribution. For the anterior and posterior section, two-way mixed ANOVAs (Group $\times$ dorsoventral Location) were performed on four groups: 35-day-old control, 55-day-old control, 10day AAE treatment group, 55-day-old with early AAE

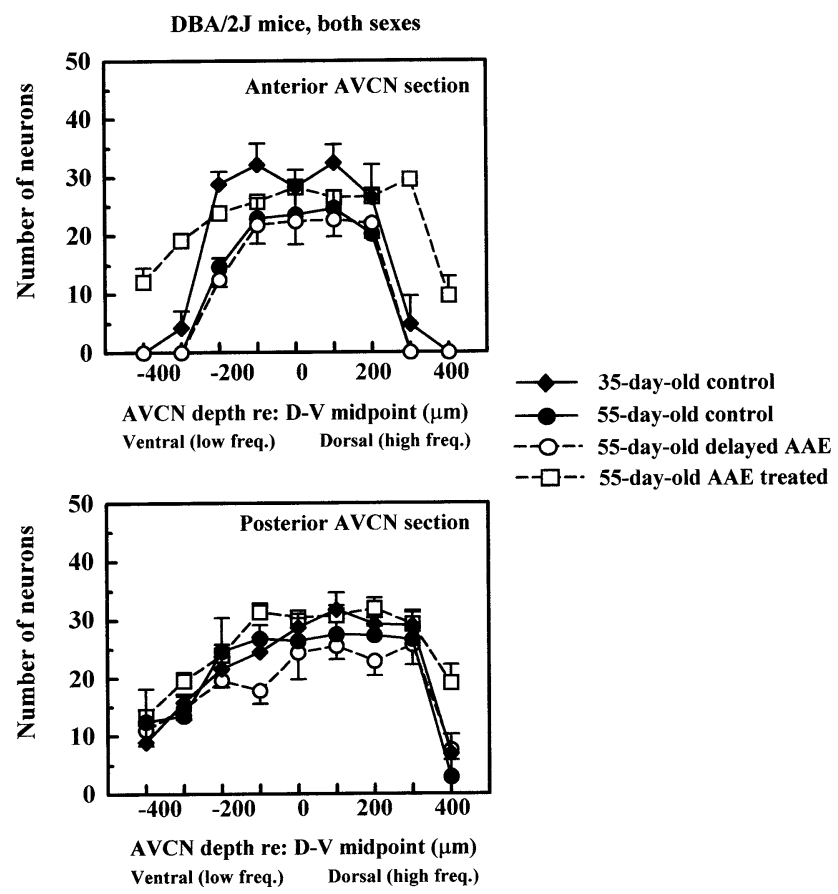

FIG. 4. Number of AVCN neurons as a function of dorsoventral location $(100-\mu \mathrm{m}$ slabs) in two standard AVCN frontal sections. AAE-treated mice (males and females combined here) received nightly treatment beginning prior to 12 days of age (unfilled squares). Neuron savings in treated mice were most pronounced in dorsal (high frequency) and ventral (low frequency) regions. treatment (sexes combined). Follow-up two-way ANOVAs were used to compare individual groups.

The anterior section is particularly interesting in that it shows the AAE-treated mice to have more neurons than the other groups in the dorsal and ventral extremes of the AVCN. The main effect of Group $\left(F_{3,26}=13.66, p<0.0001\right)$ and Group $\times$ Location interaction $\left(F_{24,208}=3.94, p<0.0001\right)$ were significant, with follow-up analyses indicating the following:

1. In control mice, there is an age-related loss of neurons by 55 days, as 35-day-old controls differed significantly from vs. 55-day-old controls $\left(F_{1.8}=\right.$ $6.57, p=0.034)$.

2. Early AAE treatment (open squares) resulted in savings. AAE-treated mice had more neurons than like-aged controls, with a main effect of Group $\left(F_{1,18}=32.64, p<0.0001\right)$ and Group $\times$ Location interaction $\left(F_{8,144}=7.16, p<0.0001\right)$. Paired comparisons (Tukey's tests) showed the differences occurred across most dorsoventral locations.

3. Delayed AAE treatment (open circles) had no effect in any dorsoventral location, as this group did not differ from controls.

Group differences in the posterior section were less clear. There was a main effect of Group $\left(F_{3,26}=5.15\right.$, $p=0.0063)$, but the Group $\times$ Location interaction was not significant.

Follow-up comparisons found that AAE-treated mice had more neurons than controls, with a significant main effect of Group $\left(F_{1,18}=8.15, p=0.01\right)$; however, with the exception of the most dorsal region, the differences were small and evenly distributed across dorsoventral locations. There were no differences between 1-month-old and 55-day-old controls or between delayed treatment group and controls.

To summarize, the savings in AVCN neurons (see Fig. 3) were spread across the entire dorsoventral extent of the AVCN in D2 mice. Large neuron savings were observed in the dorsal and ventral extremes of the anterior section in AAE-treated mice.

\section{DISCUSSION}

The ability to compare two inbred strains of mice allows one to make inferences about the generality or specificity of findings and, by implication, underlying mechanisms. Effects of AAE treatment that are common to both D2 and B6 mice suggest mechanisms that are not tightly regulated by the age or rate at which progressive hearing occurs, because these phenotypes differ substantially between the two strains. Differences in findings for the two strains would suggest that the developmental timing and/ 
or severity of hearing loss may be important in determining the outcomes. Alternatively, genetic mechanisms that are not manifested in these obvious auditory phenotypes may also be necessary or sufficient to produce the strain differences. Whereas AAE treatment had ameliorative effects on progressive elevation of ABR thresholds in D2 and B6 mice (Turner and Willott 1998; Willott and Turner 1999; present study Fig. 1), the present study found both similarities and substantive differences in the histological effects of AAE treatment on D2 mice compared to what was found in B6 mice by Willott and Bross (2004).

\section{The cochlea}

AAE treatment resulted in lessened severity of hair cell loss in the mid-cochlea of 55-day-old D2 mice whose AAE treatment was initiated by the time they began to hear. Hair cell savings were also observed in the earlier study (Willott and Bross 2004) of year-old B6 mice whose treatment began at 25 days of age. Because B6 mice show little or no cochlear damage prior to 25 days, this paradigm is similar to the "early" AAE treatment used on D2 mice in the present study. As mentioned earlier, the severity of hearing loss in 55-day-old control D2 mice is comparable to that of 12- to 14-month-old B6 mice. Thus, in both studies, AAE treatment began prior to significant cochlear degeneration and was maintained until an age that control mice exhibit substantial hearing loss. It would appear that AAE treatment can retard the loss of hair cells in both D2 and B6 mice.

Whereas the cause(s) of cochlear pathology/ hearing loss in D2 and B6 mice are not fully understood, there is evidence linking progressive hearing loss and perhaps the $A h l$ gene (Johnson et al. 1997, $2000)$ to cadherin 23 ( $C d h 23$ ) alleles in inbred mouse strains (Noben-Trauth et al. 2003; Zheng et al. 2005). Cdh23 is expressed primarily during development, but expression has been detected in adult hair cell stereocilia (Di Palma et al. 2001), and Cdh23 was proposed as the tip link (Siemens et al. 2004). Thus, one aspect of hearing loss in D2 and B6 mice is likely to involve disruption of stereocilia. To our knowledge, however, a potential mechanism associating augmented acoustic stimulation to amelioration of cadherin dysfunction is not known. A mechanism whereby AAE treatment lessens sterocilia disruption may be revealed by future research, and this might explain the slowing of ABR threshold elevations. However, the possibility of a more "general" ameliorative mechanism for AAE treatment is also attractive. It is unclear as to why spiral ganglion cells and other cochlear tissue that degenerate in B6 mice (Hequembourg and Liberman 2001; Ohlemiller and Gagnon 2004) would be affected by stereocilia disruption and/or why AAE treatment would have an effect via stereocilia. Increased auditory system activity might very well ameliorate the general condition of cochlear tissue through physiological "exercise," up-regulation of beneficial entities such as neurotrophins, and/or facilitation of cochlea-cochlear nucleus pathways. In other words, AAE treatment may help cochlear tissue survive or function better despite the actions of Cdh23 or other genes.

\section{The ACVN}

In $\mathrm{D} 2$ mice, $\mathrm{AAE}$ treatment begun as early as possible (before the onset of hearing) prevented the loss of neurons that typifies 55-day-olds (e.g., Willott and Bross 1996). When treatment was delayed until 45 days of age, there was no ameliorative effect, presumably because hearing loss and/or AVCN damage had already occurred prior to treatment. Because the loss of AVCN neurons accompanies progressive cochlear damage (Willott and Bross 1996), the working hypothesis has been that the loss of central neurons is a secondary reaction to physiological and/or anatomical deprivation of afferent input. In line with this reasoning, the slowing of progressive peripheral pathology/hearing loss by AAE treatment combined with the additional neural stimulation evoked by the AAE would counteract the deprivation process. While this activity-dependent hypothesis is parsimonious, nothing is known at this time about the specific mechanisms that may be responsible for neuron death in the AVCN or its mitigation by AAE treatment.

The Willott and Bross (2004) study found no ameliorative effects of AAE treatment on either the volume or number of surviving neurons in $\mathrm{B} 6$ mice, and indeed, AAE-treated males had reduced volume and number of AVCN neurons. For the most part, the neuronal savings in D2 mice occurred in the dorsal and ventral extremes of the AVCN, suggesting an explanation D2-B6 strain differences based on tonotopic organization. Neurons in the dorsalmost $200 \mu \mathrm{m}$ of the B6 mouse AVCN are most sensitive to frequencies higher than those encompassed by the AAE spectrum, whereas neurons in the most ventral $200 \mu \mathrm{m}$ are most sensitive to frequencies lower than those of the AAE (i.e., normal tonotopic organization). Consequently, it might be expected that the AAE treatment would only minimally stimulate these neurons. In contrast to B6 mice, tonotopic organization in the AVCN of D2 mice is abnormal (Willott et al. 1982). Because of cochlear pathology, neurons in the dorsal and ventral extremes of the AVCN never respond to high and low frequencies; moreover, the 
D2 AVCN appears to undergo early neural plasticity, such that dorsal and ventral neurons respond well to middle frequencies even at three weeks of age (Willott et al. 1982). This means that, despite histopathology of the basal and apical cochlea of D2 mice, the entire AVCN would be stimulated by the AAE noise band, presumably because input from the mid-cochlea is distributed ventrally and dorsally. The AAE would increase neural activity throughout the D2 AVCN, leading to the preservation of neurons observed in the present study.

As mentioned, Willott and Bross (2004) also found that AAE-treated B6 males exhibited more severe hearing loss than controls in the dorsal and ventral extremes of the AVCN-tonotopic regions adjacent to the mid-frequency regions stimulated by the AAE. The "limited resources" hypothesis (Willott and Bross 2004) proposes that the neurons in dorsal and ventral AVCN were deprived of glucose, oxygen, and/or other entities important for neuron survival because they were metabolized at high levels by neurons responding strongly to the AAE. The absence of this type of "negative" AAE effect in the AVCN of D2 mice is consistent with the limited resources hypothesis. Because neurons throughout the entire dorsoventral extent of the D2 AVCN are stimulated by the $\mathrm{AAE}$, there would be no deprivation in the dorsal and ventral regions. Similar reasoning might also account for the findings that ablation or very severe damage to the cochlea does not result in the loss of AVCN neurons in mice (Mostafapour et al. 2000; Willott et al. 1994), whereas basal cochlear degeneration (B6 and D2 mice) does (Willott and Bross 1996); with widespread cochlear damage, no portion of AVCN uses excessive resources.

\section{Sex differences}

Whatever is responsible for the sex difference regarding the loss of AVCN neurons in AAE-treated B6 mice (Willott and Bross 2004) is moot in the present study because there was no loss of neurons in treated D2 mice of either sex. Whereas the present study cannot speak to that issue, it does shed light on another sex difference observed in $\mathrm{B} 6$ mice. Studies of ABR thresholds show that male and female B6 mice exhibit a similar rate and severity of hearing loss until about six months of age. Then, ABR thresholds of female $\mathrm{B} 6$ mice deteriorate more rapidly than males (Henry 2002; Willott and Bross 2004). The 7-12 months age range represents a period of middle-age decline in fertility that includes with diminishing levels of estradiol, deteriorating cycle frequency, and cycle irregularity (Nelson et al. 1981, 1982, 1992). These data suggest the hypothesis that declining estrogen contributes to the emerging sex difference.
Estrogen is known to have neuroprotective properties in various regions of the brain (Garcia-Segura et al. 2001) and in the auditory system (Guimaraes et al. 2004). Thus, it is possible that in young adult B6 females, estrogen has a protective or trophic effect in the cochlea that partially checks the deleterious effects of the $A h l$ and/or other genes; this beneficial effect dissipates with the middle-aged decline in estrogen, resulting in accelerated hearing loss, especially between 10 and 12 months. If declining estrogen were responsible for the sex effect in B6 mice, it would be predicted that no sex effect would be present in $\mathrm{D} 2$ mice. Cochlear degeneration and hearing loss run their course in D2 mice well before middle age. The finding that no sex differences were observed in D2 mice of the present study is consistent with a role of declining estrogen in older B6 mice (see Willott and Bross 2004 for more details).

\section{CONCLUSIONS}

Effects of AAE treatment in D2 mice were similar to those in B6 mice (Willott and Bross 2004) in that mice of both strains exhibited lesser ABR threshold elevations and hair cell loss than age-matched controls. This finding suggests that attenuated cochlear tissue damage is manifested whether progressive hearing loss is early and rapid (D2 mice) or gradual with adult onset (B6 mice). A more important variable appears to be initiation of treatment while cochlear pathology is minimal, a finding of an earlier work as well (Willott et al. 2000). AAE treatment can slow cochlear degeneration but can not reverse it.

Although lower ABR thresholds in AAE-treated mice were accompanied by slightly reduced cochlear cell loss, numerical savings of hair cells may not be sufficient to account for the lower thresholds. AAEtreated mice exhibited threshold elevations between 30 and 55 days (albeit less than those of controls), yet few hair cells were lost in 55-day-olds (Fig. 2). This suggests the involvement of alterations in hair cell structure and/or physiology more subtle than simple elimination of cells or the involvement of other cochlear tissue. This might be a specific effect on gene actions (e.g., $A h l, C d h 23$ ) or a more "general" effect on the health of cochlear tissue.

A striking difference between D2 mice of the present study and $\mathrm{B} 6$ mice of the earlier study is the ameliorative effect of AAE treatment on the survival of AVCN neurons in D2 mice, which did not occur in B6 mice. This occurred in the dorsal and ventral extremes of the AVCN, and it was hypothesized that this was related to the abnormal tonotopic organization in D2 mice that allowed the middle-frequency AAE to stimulate neurons in these regions. At 
present, neither the mechanism(s) of AVCN neuron death in D2 mice nor the means by which increased auditory activity might provide protection are known.

\section{ACKNOWLEDGMENT}

This research was supported by R01 AG07554 (J.F.W.).

\section{REFERENCES}

Ding D, McFadden SL, Salvi RJ. Cochlear hair cell densities and inner-ear staining techniques. In: Willott JF (eds) Handbook of Mouse Auditory Research. CRC Press. Boca Raton, pp 189-204, 2001.

Di Palma F, Holme RH, Bryda EC, Belyantseva IA, Pelleggrino R, Kachar B, Steel KP, Noben-Trauth K. Mutations in Cdh23, encoding a new type of cadherin, cause stereocilia disorganization in waltzer, the mouse model for Usher syndrome type 1D. Nat. Genet. 27:103-107, 2001.

EHRET G. Peripheral anatomy and physiology. In: Willott JF (ed) Auditory Psychobiology of the Mouse. Charles C Thomas. Springfield, IL, pp 169-200, 1983.

Erway LC, Willott JF, Archer JR, Harrison D. Genetics of agerelated hearing loss in mice: I. Inbred and F1 hybrid strains. Hear. Res. 65:125-132, 1993

Garcia-Segura LM, Azcoitia I, DonCarlos LL. Neuroprotection by estradiol. Prog. Neurobiol. 63:29-60, 2001.

Guimaraes P, Zhu X, Cannon T, Kim S-H, Frisina RD. Sex differences in distortion product otoacoustic emissions as a function of age in CBA mice. Hear. Res. 192:83-89, 2004.

HENRY KR. Sex- and age-related elevation of cochlear nerve envelope response (CNER) and auditory brainstem response (ABR) thresholds in C57BL/6 mice. Hear. Res. 170:107-115, 2002.

HenRY KR, Chole RA. Genotypic differences in behavioral, physiological and anatomical expressions of age-related hearing loss in the laboratory mouse. Audiology 1:369-383, 1980.

Hequembourg S, Liberman MC. Spiral ligament pathology: a major aspect of age-related cochlear degeneration in C57BL/6 mice. J. Assoc. Res. Otolaryngol. 2:118-129, 2001.

Johnson KR, ERWAY LC, CoOK SA, Willott JF, Zheng QY. A major gene affecting age-related hearing loss in C57BL/6J mice. Hear. Res. 114:83-92, 1997.

Johnson KR, ZhENG QY, ERWAY LC. A major gene affecting agerelated hearing loss is common to at least ten inbred strains of mice. Genomics 70:171-180, 2000.

Li HS, Borg E. Age-related loss of auditory sensitivity in two mouse genotypes. Acta Oto-Laryngol. 111:827-834, 1991.

Mikaelian DO. Development and degeneration of hearing in the C57/b16 mouse: relation of electrophysiologic responses from the round window and cochlear nucleus to cochlear anatomy and behavioral responses. Laryngoscope 89:1-15, 1979.

Mostafapour SP, Cochran SL, Del Puerto NM, Rubel EW. Patterns of cell death in mouse anteroventral cochlear nucleus neurons after unilateral cochlea removal. J. Comp. Neurol. 426:561-571, 2000.

Nelson JF, Felicio LS, Osterburg HH, Finch CE. Altered profiles of estradiol and progesterone associated with prolonged estrus cycles and persistent vaginal cornification in aging C57BL/6J mice. Biol. Reprod. 24:784-794, 1981.

Nelson JF, Felicio LS, Randall PK, Sims C, Finch CE. A longitudinal study of estrus cyclicity in aging C57BL/6J mice: I. Cycle fre- quency, length and vaginal cytology. Biol. Reprod. 27:327-339, 1982.

Nelson JF, Felicio LS, Osterburg HH, Finch CE. Differential contributions of ovarian and extraovarian factors to age-related reductions in plasm estradiol and progesterone during the estrous cycle of C57BL/6J mice. Endocrinologia 130:805-810, 1992.

Noben-Trauth K, Zheng QY, Johnson KR. Association of cadherin 23 with polygenic inheritance and genetic modification of sensorineural hearing loss. Nat. Genet. 35:21-23, 2003.

Ohlemiller KK, GAGNON PM. Apical-to-basal gradients in age-related cochlear degeneration and their relationship to "primary" loss of cochlear neurons. J. Comp. Neurol. 479:103-116, 2004.

Ralls K. Auditory sensitivity in mice: Peromyscus and Mus musculus. Anim. Behav. 15:123-128, 1967.

Ryugo DK, Willard FH, Fekete DM. Differential afferent projections to the inferior colliculus from the cochlear nucleus in the albino mouse. Brain Res. 210:342-349, 1981.

Shnerson A, Pujol R. Development: anatomy, electrophysiology, and behavior. In: Willott JF (ed) Auditory Psychobiology of the Mouse. Charles C Thomas. Springfield, IL, pp 395-425, 1983.

Siemens J, Lillo C, Dumont RA, Reynolds A, Williams DS, Gillespie PG, Muller U. Cadherin 23 is a component of the tip link in hair-cell stereocilia. Nature 428:950-955, 2004.

Spongr VP, Flood DG, Frisina RD, SAlvi RJ. Quantitative measures of hair cell loss in CBA and C57BL/6 mice throughout their life spans. J. Acoust. Soc. Am. 101:3546-3553, 1997.

Trettel J, Morest KD. Cytoarchitectonic atlas of the cochlear nucleus of the mouse. In: Willott JF (ed) Handbook of Mouse Auditory Research. CRC Press. Boca Raton, pp 279-298, 2001.

Turner JG, Willott JF. Exposure to an augmented acoustic environment alters progressive hearing loss in DBA/2J mice. Hear. Res. 118:101-113, 1998 .

Willott JF. Comparison of response properties of inferior colliculus neurons of two inbred mouse strains differing in susceptibility to audiogenic seizures. J. Neurophysiol. 45:35-47, 1981.

Willott JF. Aging and the auditory system. In: Mohr U, Dungworth DL, Capen CC, Carlton WW, Sundberg JP, Ward JM (eds) Pathobiology of the Aging Mouse, ILSI Monographs on the Pathobiology of Aging Animals. ILSI Press. Washington, DC, pp 179-204, 1996.

Willott JF, Bross LS. Morphological changes in the anteroventral cochlear nucleus that accompany sensorineural hearing loss in DBA/2J and C57BL/6J mice. Brain Res. Dev. Brain Res. 91: 218-226, 1996.

Willott JF, Bross LS. Effects of prolonged exposure to an augmented acoustic environment on the auditory system of middle-aged C57BL/6J mice: cochlear and central histology and sex differences. J. Comp. Neurol. 472:358-370, 2004.

Willott JF, ShNerson A. Rapid development of tuning characteristics of inferior colliculus neurons in mouse pups. Brain Res 148:230-233, 1978

Willott JF, Turner JG. Prolonged exposure to an augmented acoustic environment ameliorates age-related auditory changes in C57BL/6J and DBA/2J mice. Hear. Res. 135:78-88, 1999.

Willott JF, Demuth RM, Lu SM, Van Bergem P. Abnormal tonotopic organization in the ventral cochlear nucleus of the hearing-impaired DBA/2 mouse. Neurosci. Lett. 34:13-17, 1982.

Willott JF, Kulig J, SAtterfield T. The acoustic startle response in DBA/ 2 and C57BL/6 mice: relationship to auditory neurona response properties and hearing impairment. Hear. Res. 16:161-167, 1984.

Willott JF, Jackson LM, Hunter KP. Morphometric study of the anteroventral cochlear nucleus of two mouse models of presbycusis. J. Comp. Neurol. 260:472-480, 1987. 
Willott JF, Bross LS, McFadden SL. Morphology of the cochlear nucleus in $\mathrm{CBA} / \mathrm{J}$ mice with chronic, severe sensorineural cochlear pathology induced during adulthood. Hear. Res. 74:1-21, 1994.

Willott JF, Turner JG, Sundin VS. Effects of exposure to an augmented acoustic environment on auditory function in mice: roles of hearing loss and age during treatment. Hear. Res. 142:79-88, 2000.

Zheng QY, Yan D, OuYang XM, Du LL, Yu H, Chang B, Johnson KR, LiU XZ. Digenic inheritance of deafness caused by mutations in genes encoding cadherin 23 and protocadherin 15 in mice and humans. Hum. Mol. Genet. 14:103-111, 2005. 